\title{
The same esterase B1 haplotype is amplified in insecticide-resistant mosquitoes of the Culex pipiens complex from the Americas and China
}

\author{
CHUAN-LING QIAO* \& MICHEL RAYMOND $\dagger$ \\ Institut des Sciences de l'Evolution (URA CNRS 327), Laboratoire Gènétique et Environnement, Université de \\ Montpellier II (C.C. 065), F-34095 Montpellier cedex 05, France
}

\begin{abstract}
In Culex pipiens, overproduction of nonspecific esterases is a common mechanism of resistance to organophosphate insecticides. The esterases are attributed to closely linked loci named $A$ and $B$, and overproduction of all esterases B is due to gene amplification. In order to determine if the esterase B1 identified by electrophoretic studies in Culex pipiens mosquitoes from different countries is overproduced due to the amplification of the same DNA haplotype, the amplified region encompassing the structural esterase $B 1$ gene was characterized by restriction mapping and RFLP. The same amplified haplotype was found in mosquitoes with an esterase B1 protein, independently of their geographical origin: French Guiana, Venezuela, Puerto Rico, California and China. Large variations in amplification levels were observed. It is concluded that B1 amplification has a unique origin, either in America or in Asia, and has subsequently spread by migration. This migration is more limited than that of $A 2-B 2$ esterases, since $B 1$ is confined to the Americas, the Carribean and part of China, whereas the A2-B2 distribution now includes the Americas, the Carribean, Asia, Africa, the Pacific islands and Europe.
\end{abstract}

Keywords: Culex pipiens, gene amplification, insecticide resistance, migration, RFLP.

\section{Introduction}

In mosquitoes of the Culex pipiens complex, increased esterase detoxification by two types of esterases ( $A$ and B) is a frequent mechanism of resistance to organophosphorous insecticides (OP). Eight esterases of high activity have been observed in natural populations: esterase A1 in Mediterranean countries, esterase B1 in North America, and three groups of associated esterases: $\mathrm{A} 2$ and $\mathrm{B} 2$ in numerous countries of three continents, A4 and B4 in the eastern Mediterranean, and A5 and B5 in Cyprus (Pasteur \& Georghiou 1989; Pasteur et al., 1981; Raymond et al., 1991; Poirié et al., 1992; Severini et al., 1993; Raymond \& Marquine 1994; Chevillon et al., 1995). The large increase in esterase activity observed in OP-resistant mosquitoes is due to the overproduction of the enzymes, resulting from the amplification of a DNA sequence containing the corresponding structural gene in the case of esterases B (Mouchès et al., 1986, 1990; Raymond et al., 1991; Poirié et al., 1992).

*Present address: Institute of Zoology, Academia Sinica, Beijing, 100080 , China.

†Correspondence.
The identification of overproduced esterase proteins in natural populations relies on their electrophoretic characteristics (mobility and substrate preference, $\alpha$ - and $\beta$-naphthyl acetates for esterases $A$ and $\mathrm{B}$, respectively), and the linkage of alleles of the $A$ and $B$ esterase genes. All esterases B2 identified by these criteria have been shown to correspond to the amplification of the same haplotype, which has never been found in a mosquito lacking an amplified esterase B (Raymond et al., 1991, and unpublished data). But these criteria cannot discriminate between the overproduced esterases B4 and B5, which have the same electrophoretic mobility in standard conditions (but are not identical) and are also associated with electrophoretically similar esterases A (A4 and A5, Poirié et al., 1992). Although electrophoretic studies have revealed the presence of esterase B1 in many localities of the U.S.A. (Beyssat-Arnaouty et al., 1989; Pasteur \& Georghiou, 1989), Central America and Asia (Georghiou, 1992), the esterase B1 haplotype has only been characterized in the Californian reference TEM-R strain (Mouchès et al., 1990, Raymond et al., 1991). The present study was thus undertaken to determine whether electrophoretically identical 
esterases B1 from different countries correspond to the same amplified haplotype.

\section{Materials and methods}

\section{Mosquitoes}

The mosquito populations included three laboratory strains (TEM-R, EDIT and BEIJING), and three field samples (CAYENNE, PUNTA and RICO). TEM-R is the esterase B1 reference strain derived from a Californian population collected in 1974 (Ranasinghe \& Georghiou, 1979, Georghiou et al., 1980), and recently made homozygous for the presence of overproduced esterase B1 (Raymond et al., 1993). EDIT derives from crosses between the SUTTER-YUBA strain (derived from larvae collected in 1988 in California by G. P. Georghiou, University of California, Riverside) and the susceptible S-LAB reference strain (Georghiou et al., 1966); it was founded with the offspring of one female SUTTER-YUBA $\times$ S-LAB crossed with one $S$-LAB male, and selected by single pair-crosses between adults with esterase B1 until homozygosity of esterase $B 1$ was attained. All mosquitoes of the EDIT strain thus contain an esterase $B 1$ gene amplification identical by descent on each homologous chromosome. BEIJING is derived from larvae collected in July 1992 west of Beijing (China), and subsequently selected with temephos every generation. PUNTA, CAYENNE and RICO are three field samples collected as larvae in March 1991 in Punta del Este (Venezuela), in June 1991 in Cayenne (French Guiana), and in February 1992 in San Juan (Puerto Rico), respectively. Adults from each strain or field collection were stored in liquid nitrogen until the present study.

\section{Starch gel electrophoresis}

Presence or absence of highly active esterases was determined in single mosquito homogenates, using starch gel electrophoresis with Tris-Maleate-EDTA buffer systems (Pasteur et al., 1988). Each gel contained mosquito extracts from the following reference strains: BARRIOL with esterase A1 (Pasteur \& Raymond, unpublished), VIM with esterases A4 and B4 (Poirié et al., 1992), TEM-R with esterase B1 (see above), and SELAX with esterases A2 and B2 (Wirth et al., 1990).

\section{Restriction maps}

Genomic DNA was extracted from a pool of 100 adults according to Raymond et al. (1989), digested with one or several restriction enzymes (AccI, BclI,
BamHI, BglII, EcoRI, EcoRV, HindIII, KpnI, PstI, SacI, SalI, XbaI, XhoI), run on agarose gels, transferred onto a Nylon membrane according to Sambrook et al. (1989), prehybridized and hybridized with the 1.3 kb B1 cDNA probe of Mouchès et al. (1990).

\section{RFLP on single mosquitoes}

Single mosquito genomic DNA was obtained using a simplification of a method provided by C. Malcolm (QMW, University of London, England). Each mosquito was homogenized in $150 \mu \mathrm{L}$ of buffer ( 1 per cent SDS, $50 \mathrm{~mm}$ Tris $\mathrm{HCl} \mathrm{pH} \mathrm{8.0,25} \mathrm{mM} \mathrm{NaCl,} 25 \mathrm{~mm}$ EDTA, pH 8.0) using a polypropylene pestle, and incubated at $65^{\circ} \mathrm{C}$ for $30 \mathrm{~min}$. One hundred $\mu \mathrm{L}$ of a 3 M K-acetate solution were added into each homogenate, which was left one hour on ice and then centrifuged for $10 \mathrm{~min}$ at $10000 \mathrm{~g}$. DNA was precipitated by adding two volumes of ethanol to each supernatant. This produced enough DNA to carry out a digestion with one restriction enzyme $(E c o$ RI) which differentiates all known amplified haplotypes (Raymond et al., 1991; Poirié et al., 1992). Gel migration, transfer, probe labelling (the $1.3 \mathrm{~kb} \mathrm{cDNA}$ of $\mathrm{B} 1$ esterase), and hybridization were done as described in Raymond $e t$ al. (1989). After migration, a picture of each gel was obtained to control for the amount of DNA loaded in each lane, and to help the quantitative interpretation of the results. EcoRI digests were also performed on 1-5 $\mu \mathrm{g}$ DNA from mosquitoes with known haplotypes and were run on each gel as a control: $B 2$ (strain SELAX) and $B I$ (strain TEM-R).

\section{Results}

\section{Protein identification}

A highly active esterase of the same substrate preference and electrophoretic mobility as esterase B1 in TEM-R mosquitoes was detected in lab or field mosquitoes (Table 1) from China (BEIJING), South America (PUNTA and CAYENNE), the Caribbean (RICO), and North America (EDIT). In addition, we observed esterases A2-B2 in CAYENNE mosquitoes, and two new esterases of high activity, preferentially hydrolysing $\alpha$-naphthyl acetate. One esterase had an electrophoretic mobility very similar but not identical to $\mathrm{A} 2$, and was present in mosquitoes from South America (CAYENNE and PUNTA) which also possessed esterase $\mathrm{B} 1$; it will be provisionally designated as A6 until further characterized. The other was found in mosquitoes from South America (CAYENNE and PUNTA) and the Caribbean (RICO), and was identical to esterase $\mathrm{C} 2$ (which probably 
belongs to a separate locus) observed in a recent study of Martinique populations (Yébakima et al., 1994).

\section{Esterase $B$ haplotype characterization}

Restriction maps of the amplified DNA region hybridizing with esterase B1 cDNA were built using 13 restriction enzymes for the TEM-R, EDIT, BEIJING and RICO samples, where esterase $\mathrm{B} 1$ protein was the only overproduced esterase B and was present in all (TEM-R and EDIT) or most mosquitoes (Table 1).
The same restriction map was obtained with all samples (Fig. 1), but variations in the number of gene copies were observed between samples. Considering the amount of DNA loaded in each well and the radioactivity of the DNA fragments hybridizing with the esterase $\mathrm{B} 1 \mathrm{cDNA}$ probe, it can be concluded that the number of gene copies was much higher in TEM-R than in the other samples (data not shown). These variations are difficult to interpret for BEIJING and RICO mosquitoes which were not homozygous for the presence of esterase $\mathrm{B} 1$, but they clearly indicate

Table 1 Origin of the mosquito samples or strains used, and the identification of their overproduced or highly active A or B esterase proteins

\begin{tabular}{|c|c|c|c|}
\hline Mosquitoes & Country & A or B overproduced esterase & References \\
\hline \multicolumn{4}{|c|}{ Reference strains } \\
\hline SELAX & USA, CA & $\mathrm{A} 2-\mathrm{B} 2$ & Wirth et al., 1990 \\
\hline TEM-R & USA, CA & B1 & Georghiou et al., 1980 \\
\hline VIM & France & A4-B4 & Poirié et al., 1992 \\
\hline BARRIOL & France & $\mathrm{A} 1$ & Pasteur et al., unpublished \\
\hline \multicolumn{4}{|l|}{ Strains } \\
\hline BEIJING & China & B1 & This study \\
\hline EDIT & USA, CA & B1 & This study \\
\hline \multicolumn{4}{|l|}{ Field samples } \\
\hline $\mathrm{RICO}$ & Puerto-Rico & B1 & This study \\
\hline CAYENNE & French Guiana & $\mathrm{B} 1, \mathrm{~A} 2-\mathrm{B} 2, \mathrm{C} 2, \mathrm{~A} 6$ & This study \\
\hline PUNTA & Venezuela & $\mathrm{B} 1, \mathrm{C} 2, \mathrm{~A} 6$ & This study \\
\hline
\end{tabular}

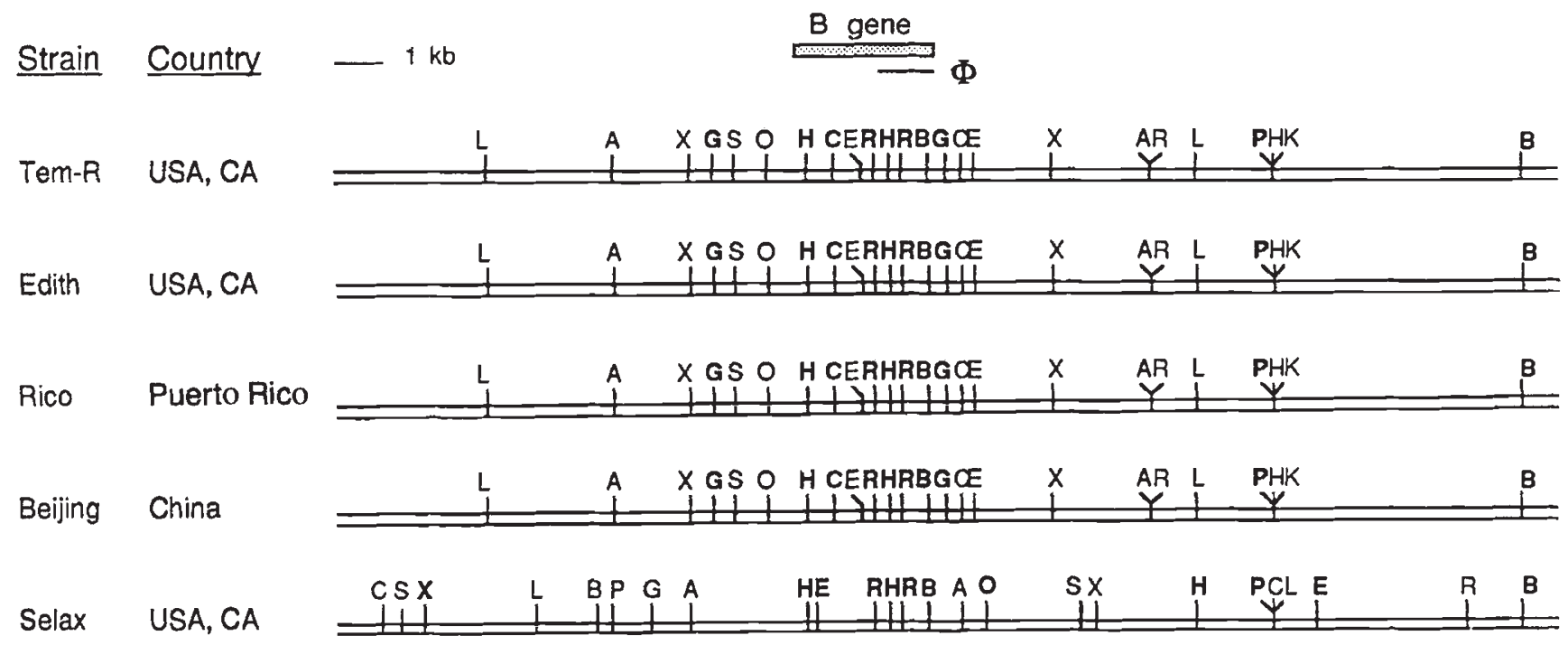

Fig. 1 Restriction maps of the esterase $B$ genes and their flanking sequences from the B1 reference strain (TEM-R), three strains or wild samples possessing the B1 overproduced protein (EDIT, RICO and BEIJING) and the B2 reference strain (SELAX). Restriction enzymes are abreviated as: A (AccI), B (BamHI), C (BcII), G (BglII), E (EcoRI), R(EcoRV), H (HindIII), $\mathrm{K}(K p n \mathrm{I}), \mathbf{P}(P s t), \mathrm{S}($ SacI $), \mathbf{L}($ SalI $), \mathrm{X}(X b a \mathrm{I})$ and $\mathrm{O}(X h o \mathrm{I})$. The localization of the esterase $B$ gene is indicated by the shaded box and the $1.3 \mathrm{~kb}(\Phi) \mathrm{cDNA}$ probe by a line below. Only the sites flanking the fragment to which the probe hybridized are mapped for each enzyme. 
distinct levels of gene amplification in EDIT and TEM-R mosquitoes which are both homozygous for the presence of esterase B1.

\section{Esterase $B$ haplotype characterization in single mosquitoes}

Because of the small amount of genomic DNA extracted from a single mosquito, only one restriction enzyme $(E c o \mathrm{RI})$ was used to characterize esterase B haplotypes. With this endonuclease, the esterase $B 1$ haplotype yields an amplified fragment of $2.1 \mathrm{~kb}$, whereas the esterase $B 2$ haplotype yields a fragment of $9 \mathrm{~kb}$ (see Fig. 1 and Raymond et al., 1991).

Six out of 15 PUNTA (Venezuela) mosquitoes (Fig. 2) displayed an amplified $2.1 \mathrm{~kb}$ band characteristic of the esterase $B 1$ haplotype, as expected from the electrophoretic identification of esterase B1 protein which disclosed 30 out of 58 mosquitoes with B1 (Fisher exact test on contingency table, $P>0.35$ ). No mosquito had an amplified $9 \mathrm{~kb}$ band typical of the esterase $B 2$ haplotype, which also is in agreement with electrophoretic data (Table 1), and one had an amplified $1.3 \mathrm{~kb}$ band (Fig. 2, mosquito no. 9) corresponding to none of the amplified haplotypes described so far. The nine mosquitoes lacking an amplified band (Fig. 2, lanes nos 2-6, 8, 10, 13 and 15) displayed two bands of various sizes from which at least eight alleles could be identified; none of these mosquitoes had the same genotype.

Thirteen out of 16 CAYENNE (French Guiana) mosquitoes (Fig. 3) displayed an amplified $2.1 \mathrm{~kb}$ band characteristic of the esterase $B 1$ haplotype, four had an amplified $9 \mathrm{~kb}$ band that may correspond to the esterase $B 2$ haplotype (Fig. 3, nos 5, 8, 13 and 15) and one (Fig. 3, no. 3) had no amplified band.

Two additional observations were made from the single mosquito study. The first concerns the number of copies of the esterase $B 1$ haplotype. This number was clearly lower in PUNTA and CAYENNE than in TEM-R mosquitoes: although about 10 times less DNA was loaded in TEM-R wells, the radioactivity of the TEM-R band was equivalent to or higher than PUNTA and CAYENNE B1 bands. In addition, large differences in copy number were observed between mosquitoes of the same population (e.g. lanes nos 16 and 14 of Fig. 3 displayed the same intensity of the 2.1 $\mathrm{kb}$ band, but lane no. 14 was loaded with five times more DNA than lane no. 16).

The second observation concerns two DNA fragments of 3 and $5.6 \mathrm{~kb}$ ( $\mu$ and $v$ in Figs 2 and 3 ) which hybridized with esterase B1 cDNA in several (four of the six PUNTA, and nine of the 13 CAYENNE) mosquitoes with the amplified $2.1 \mathrm{~kb}$ fragment. When comparison within each lane can be made (avoiding variations due to differences in DNA amount), these two bands displayed a much lower radioactivity than the $2.1 \mathrm{~kb}$ band. They were also observed in TEM-R, EDIT and RICO but not in BEIJING mosquitoes, where they seemed to be replaced by three other bands (of the same low intensity as $\mu$ and $\nu$ ) of 2.6, 3.2 and $4.2 \mathrm{~kb}$. The exact nature of these bands is unknown, and they could represent (1) a polymorphism within the B1 amplification or (2) incomplete digestion

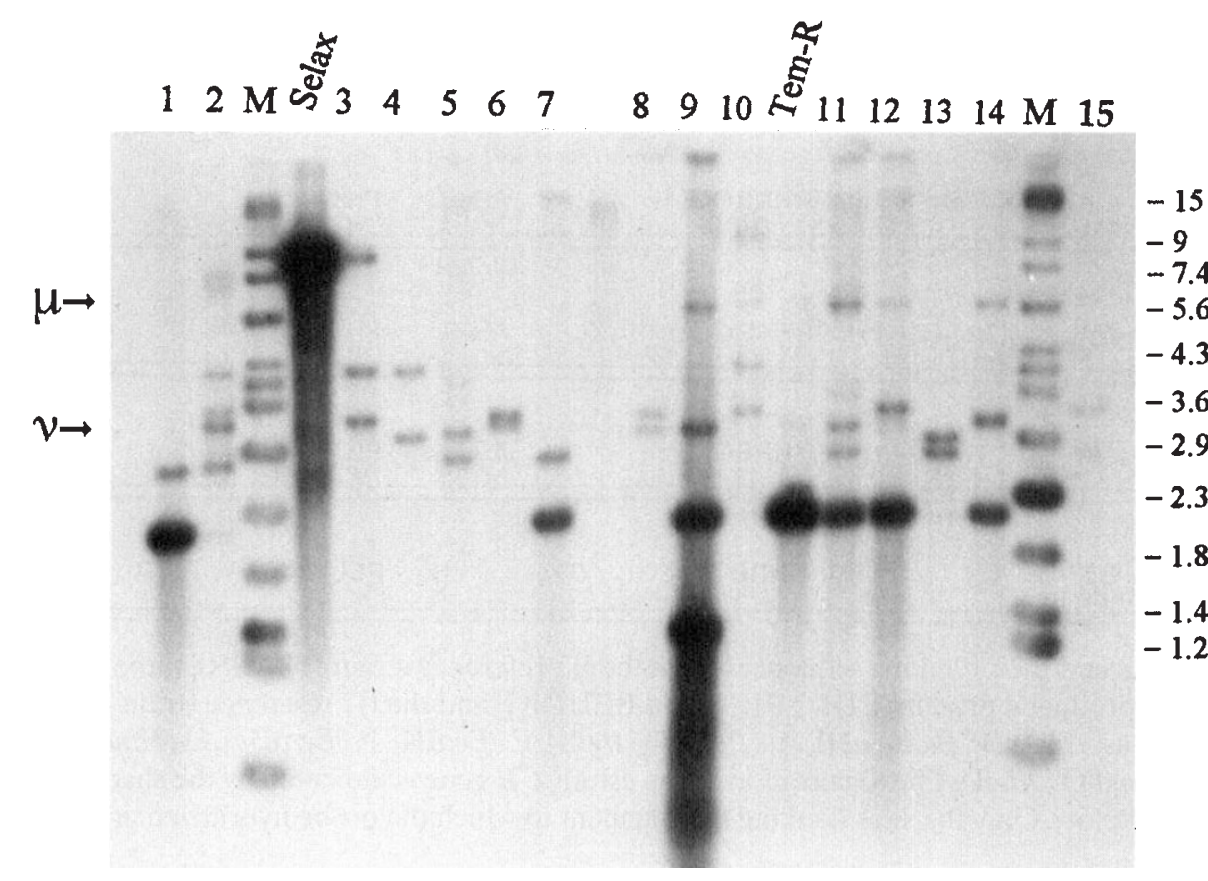

Fig. 2 RFLP on single mosquitoes from the PUNTA field sample. Sixteen wells loaded with field mosquitoes are numbered on top. $M$ refers to the size marker (in kb on the right). DNAs from SELAX and TEM-R reference strains were loaded as controls. Single copy bands $(\mu$ and $v)$ associated with B1 amplification are indicated. Supernumerary bands in individuals nos 2 and 3 are considered to be artefactual: digestion was not complete for individual nos 2 , and the upper $9 \mathrm{~kb}$ band in individual no. 3 is probably a contamination from the SELAX well. 
Fig. 3 RFLP on single mosquitoes from the CAYENNE field sample. Sixteen wells loaded with field mosquitoes are numbered on top. $\mathrm{M}$ refers to the size marker (in $\mathrm{kb}$ on the right). DNAs from SELAX and TEM-R reference strains were loaded as controls. Single copy bands $(\mu$ and $\nu)$ associated with $\mathrm{B} 1$ amplification are indicated.

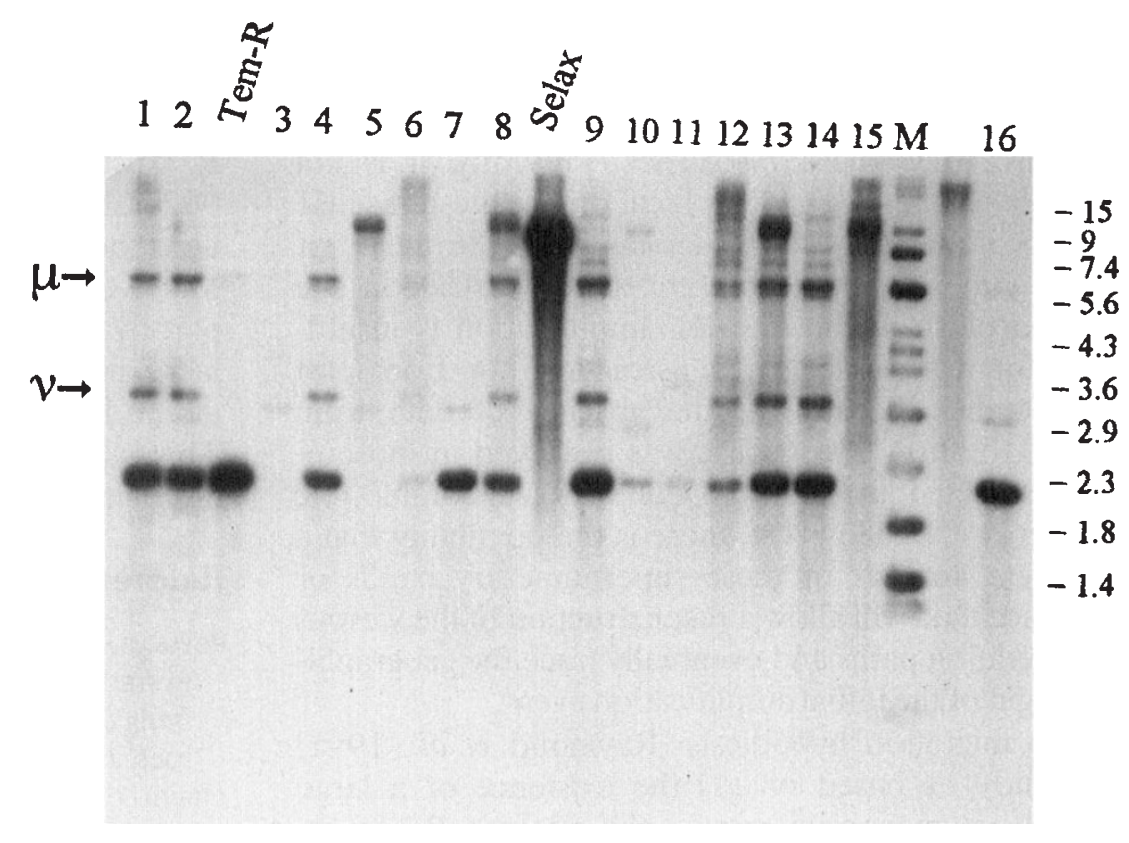

products. In single mosquitoes the intensity of these bands is about the same as that of the nonamplified and polymorphic alleles, as can be seen in Fig. 2 where the DNA content in each lane is approximately the same, except in the TEM-R lane which contains less DNA.

\section{Discussion}

The present study shows that mosquitoes with an overproduced esterase B1 from China (BEIJING), North America (EDIT and TEM-R), and the Caribbean (RICO) have an identical amplified haplotype with respect to their restriction sites with 13 endonucleases. The analysis of single mosquitoes from South America (CAYENNE and PUNTA) revealed the presence of the EcoRI $2.1 \mathrm{~kb}$ fragment typical of the esterase $B 1$ haplotype in many mosquitoes. Although a more detailed study of South American populations is needed, it seems that the same esterase $B 1$ haplotype is also amplified in Culex pipiens populations from these countries.

Previous studies (Raymond et al., 1991, and unpublished data) have shown an extremely large polymorphism of the region encompassing the esterase $B$ gene when it is not amplified. A similar observation was noted in mosquitoes from South America: at least eight alleles could be deduced from the nine PUNTA mosquitoes lacking an amplification (Fig. 2). As Raymond et al. (1991) pointed out, such a large polymorphism makes it very unlikely that the same haplotype could become amplified in two different geographical regions. Thus, as for esterase B2, we can conclude that amplification of the esterase B1 haplotype derives from a unique event which occurred in a specific population. The existence of variations in the number of esterase $B 1$ copies between mosquitoes of the same geographical area (e.g. California or French Guiana) or of different geographical areas, indicates that this unique event was followed by other events which have increased the number of gene copies within each amplification. Previous studies by Pasteur et al. (1984) that looked at resistance levels and esterase B1 activity in mosquitoes homozygous for the presence of different esterase $B 1$ alleles (i.e. what we would call today different 'amplified alleles'), indicated that, in California in 1979, there were at least four levels of esterase B1 amplification. In contrast to the first amplification event, those that follow and increase the number of copies are therefore very common, and they most probably can occur repeatedly in the same or in different populations. As a consequence, the overall B1 amplification organization may differ in mosquitoes from distinct geographical areas. These differences thus probably reflect the different histories of copy proliferation from the initial event which was at the origin of the multiplication of the $B 1$ haplotype.

The nature of the supernumerary bands is unknown. Their occurrence in association with amplified fragments (e.g. $\mu$ and $v$ bands in North and South America) suggests that they are closely linked to the B1 amplification, and it is possible that they correspond to a polymorphism within the amplification or to incomplete digestion products. The presence of the supernumerary bands $\mu$ and $\nu$ in strains or samples from the 
Americas and the Carribean, and their absence from China further suggests that $B 1$ alleles from the Americas are more closely related to one another than they are to Chinese $B 1$ alleles. Presently, it is not possible to infer the geographical origin of esterase B1 amplification (e.g. the Americas, the Carribean or Asia), either from the present study (restriction site polymorphism within the B1 amplification is insufficient for a phylogenic reconstruction), or from past field studies, because of the absence of data from China (the first B1 esterase was observed in mosquitoes collected in 1974 in California, Georghiou \& Pasteur, 1978). However, there is the possibility that a complete analysis of these supernumerary bands or sequence data will allow a reconstruction of the various B1 migration paths and eventually trace the geographical origin of the initial amplification event.

The migration hypothesis (Raymond et al., 1991; this study) is based on (1) the existence of a large neutral polymorphism around the esterase $B$ gene in susceptible mosquitoes, and on (2) the presence of the same amplified haplotype (characterized mainly by neutral polymorphisms) in populations from distant geographical areas. This hypothesis has been recently questioned (Hemingway et al., 1993; Ketterman et al., 1993 ) on the basis of biochemical evidence, but alternative explanations for the similarity of restriction maps have not been proposed. We consider that data on protein quantitative parameters $\left(K_{\mathrm{m}}, k_{\mathrm{a}}, V_{\mathrm{m}}\right)$ cannot be used to undermine a hypothesis based on qualitative genetic data.

Four amplification events have been detected so far, each one with a very distinct haplotype (Mouchès et al., 1986; Raymond et al., 1989; 1991; Poirié et al., 1992). Two of them, B1 and B2, have migrated extensively and reached at least three continents (Raymond et al., 1991; Rivet et al., 1993; this study) from a still unknown geographical origin. The other two are present only in Mediterranean countries (Poirié et al., 1992; Raymond \& Marquine, 1994). An understanding of the present situation may help to predict the evolution of resistance genes in the wild and facilitate resistance management. Biochemical studies on isolated strains have been useful to identify and characterize resistance genes, but only population studies and the use of adequate molecular techniques are able to solve key issues on the evolution of insecticide resistance.

\section{Acknowledgements}

We are very grateful to C. Chevillon, B. Delay, and P. Reiter for their valuable contribution in collecting populations in South America and Puerto Rico. We thank N. Pasteur and two anonymous reviewers for helpful suggestions, E. Dupont for her help in selecting the EDIT strain, C. Poteau for a 'stage annexe au DEA', R. Tustain for a 'Molecular Biology Project' (220/ 0024), M. Marquine, C. Bernard and F. Plenat for technical help. Q. C.-L. was the recipient of an EEC Marie-Curie fellowship, and research was supported in part by EEC subsidy and grants from the Ministère de la Recherche (no. 91-C-0939) and the Institut National de la Recherche Agronomique (no. 92/190/4800). This is paper no. 94.039 of the Institut des Sciences de l'Evolution.

\section{References}

BEYSSAT-ARNAOUTY, V., MOUCHES, C., GEORGHIOU, G. P. AND PASTEUR, N. 1989. Detection of organophosphate detoxifying esterases by dot-blot immunoassay in Culex mosquitoes. J. Am. Mosq. Control Ass., 5, 196-200.

CHEVILloN, C., PASTEUR, N., MARQuiNe, M., HEYSE, D. AND RAYMOND, M. 1995. Population structure and dynamics of selected genes in the mosquito Culex pipiens. Evolution, in press.

GEORGHIOU, G. P. 1992. World distribution of esterases involved in organophosphate resistance in Culex mosquitoes, and methods for detection. In: Otto, D. and Weber, B. (eds) Insecticides: Mechanisms of Action and Resistance, pp. 407-408. Intercept, Andover.

GEORGHIOU, G. P., METCALF, R. L. AND GIDDEN, F. E. 1966. Carbamate resistance in mosquitoes: selection of Culex pipiens fatigans Wied. (=Culex quinquefasciatus) for resistance to Baygon. Bull. W.H.O., 35, 691-708.

GEORGHIOU, G. P. AND PASTEUR, N. 1978. Electrophoretic pattern in insecticide resistant and susceptible mosquitoes. J. Econ. Entomol., 71, 201-205.

GEORGHIOU, G. P., PASTEUR, N. AND HAWLEY, M. K. 1980. Linkage relationships between organophosphate resistance and a highly active esterase B in Culex pipiens quinquefasciatus Say from California. J. Econ. Entomol., 73, 301-305.

HEMINGWAY, J., KETTERMAN, A. J., KARUNARATNE, S. H. P. P., JAYAWARDENA, K. G. I. AND VAughan, A. 1993. Amplified esterases $\mathrm{A} 2$ and $\mathrm{B} 2$. Has resistance occurred once or several times? In: Widley, K. B. and Robinson, W. H. (eds) Proceedings of the 1st International Conference on Insect Pests in the Urban Environment, pp. 319-328. BPCC Wheatons Ltd, Exeter.

KETTERMAN, A. J., KARUNARATNE, S. H. P. P., JAYAWARDENA, K. G. I. AND HEMINGWAY, J. 1993. Qualitative differences between populations of Culex quinquefasciatus in both the esterases A2 and B2 which are involved in insecticide resistance. Pest. Biochem. Physiol., 47, 199-133.

MOUCHES, C., PASTEUR, N., BERGE, J. B., HYRIEN, O., RAYMOND, M., ROBERT DE SAINT VINCENT, B., DE SILVESTRI, M. AND GEORGHIOU, G. P. 1986. Amplification of an esterase gene is responsible for insecticide resistance in a California Culex mosquito. Science, 233, 778-780.

MOUCHES, C., PAUPlin, Y., AGARWAL, M., LEMIEUX, L., HeRZOG, M., ABADON, M., BEYSSAT-ARNAOUTY, V., HYRIEN, O., ROBERT DE 
SAINT VINCENT, B., GEORGHIOU, G. P. AND PASTEUR N. 1990. Characterization of amplification core and esterase B1 gene responsible for insecticide resistance in Culex. Proc. Natl. Acad. Sci. U.S.A., 87, 2574-2578.

PASTEUR, N., GEORGHIOU, G. P. AND ISEKI, A. 1984. Variation in organophosphate resistance and esterase activity in Culex quinquefasciatus Say from California. Génét. Sél. Évol., 16, 271-284.

PASTEUR, N. AND GEORGHIOU, G. P. 1989. Improved filter paper test for detecting and quantifying increased esterase activity in organophosphate-resistant mosquitoes (Diptera: Culicidae). J. Econ. Entomol., 82, 347-353.

PASTEUR, N., PASTEUR, G., CATALAN, J., BONHOMME, F. AND BRITTONDAVIDIAN, J. 1988. Practical Isozyme Genetics. Ellis Horwood, Chichester.

PASTEUR, N., SINEGRE, G. AND GABINAUd, A. 1981. Est-2 and Est3 polymorphism in Culex pipiens $\mathrm{L}$. from southern France in relation to organophosphate resistance. Biochem. Genet., 19, 499-508.

POIRIE, M., RAYMOND, M. AND PASTEUR, N. 1992. Identification of two distinct amplifications of the esterase B locus in Culex pipiens L. mosquitoes from Mediterranean countries. Biochem. Genet., 30, 13-26.

RANASINGHE, L. E. AND GEORGHIOU, G. P. 1979. Comparative modification of insecticide-resistance spectrum of Culex pipiens fatigans Wied. by selection with temephos and temephos/synergist combinations. Pest. Sci., 10, 502-508.

RAYMOND, M., BEYSSAT-ARNAOUTY, V., SIVASUBRAMANIAN, N., MOUCHĖS C., GEORGHIOU, G. P. AND PASTEUR, N. 1989. Diversity of the amplification of various esterases $B$ responsible for organophosphate resistance in Culex mosquitoes. Biochem. Genet., 27, 417-423.

RAYMOND, M., CALlAGHAN, A., FORT, P. AND PASTEUR, N. 1991. Worldwide migration of amplified insecticide resistance genes in mosquitoes. Nature, 350, 151-153.

RAYMOND M. AND MARQUINE, M. 1994. Evolution of insecticide resistance in Culex pipiens populations: the Corsican paradox. J. Evol. Biol., 6, 315-334.

RAYMOND, M., POULIN, E., BOIROUX, V., DUPONT, E. AND PASTEUR, N. 1993. Stability of insecticide resistance due to amplification of esterase genes in Culex pipiens. Heredity, 70, 301-307.

RIVET, Y., MARQUINE, M. AND RAYMOND, M. 1993. French mosquito populations invaded by A2-B2 esterases causing insecticide resistance. Biol. J. Linn. Soc., 49, 249-255.

SAMBROOK, J., FRITSCH, E. F. AND MANIATIS, T. 1989. Molecular Cloning: A Laboratory Manual. Cold Spring Harbor Laboratory Press, Cold Spring Harbor, New York.

SEVERINI, C., ROMI, R., MARINUCCI, M. AND RAYMOND, M. 1993. Mechanisms of insecticide resistance in field populations of Culex pipiens from Italy. J. Am. Mosq. Contr. Ass., 9, 164-168.

WIRTH, M. C., MARQUiNe, M., GEORGHIOU, G. P. AND PASTEUR, N. 1990. Esterases A2 and B2 in Culex quinquefasciatus (Diptera: Culicidae): role in organophosphate resistance and linkage studies. J. Med. Entomol., 27, 202-206.

YébAKIMA, A., RAYMOND, M., MARQUINE, M. AND PASTEUR, N. 1995. Resistance to organophosphorous insecticides in Culex pipiens quinquefasciatus from Martinique. J. Med. Entomol., 32, in press. 